\title{
LEER LOS MOVIMIENTOS SOCIALES DESDE EL INDIVIDUALISMO: REFLEXIONES A PARTIR DE LATINOAMÉRICA
}

\author{
Kathya Araujo ${ }^{1}$ \\ DANilo MartucCelli ${ }^{2}$
}

\begin{abstract}
RESUMEN: La articulación entre el individualismo y los movimientos sociales es una cuestión ampliamente debatida en las ciencias sociales estadounidenses o europeas, pero relativamente ausente en el marco de la sociología latinoamericana. El artículo propone explorar este vínculos a través de tres grandes movimientos. En primer lugar, recuerda brevemente las maneras cómo el lazo entre individualismo y movimientos sociales ha sido habitualmente analizado en las ciencias sociales. En un segundo momento, se sugieren las maneras en que deben entenderse en el contexto de América Latina tanto el individualismo como los movimientos sociales. Por último, y a partir de esta reconsideración, se presentan las tensiones especificas entre ambos fenómenos sociales en la región.
\end{abstract}

Palabras-clave: Individualismo. Movimientos sociales. Acción colectiva. Hiper-actor. Individualismo agentico.

\section{UNDERSTANDING THE SOCIAL MOVEMENTS FROM THE PERSPECTIVE OF INDIVIDUALISM: REFLECTIONS FROM LATIN AMERICA}

\begin{abstract}
The articulation between individualism and social movements is a widely debated issue in US American or European social sciences, but it remains relatively absent within the framework of Latin American sociology. This paper proposes to explore this link through three major movements. Firstly, it briefly revises the ways in which the link between individualism and social movements has been routinely analyzed in social sciences. Secondly, it suggests the ways in which both individualism and social movements should be understood in the context of Latin America. Finally, from this reconsideration, it analyzes the specific tensions between both social phenomena in this region.
\end{abstract}

Keywords: Individualism. Social movements. Collective action. Hyper-actor. Agentic individualism.

El presente artículo se inscribe en el marco del Proyecto Fondecyt n. 1180338, "Problematizaciones del Individualismo en América del Sur". 1.Instituto de Estudios Avanzados - Universidad de Santiago de Chile - Santiago, Chile. E-mail: kathya.araujo@usach.cl 


\title{
LER OS MOVIMENTOS SOCIAIS DA PERSPECTIVA DO INDIVIDUALISMO: REFLEXÕES DA AMÉRICA LATINA
}

\begin{abstract}
RESUMO: A articulação entre individualismo e movimentos sociais é uma questão amplamente debatida nas ciências sociais estadunidenses e europeias, mas relativamente ausente no quadro da sociologia latino-americana. O artigo propõe explorar essa ligação por meio de três grandes movimentos. Primeiramente, discute-se brevemente sobre as maneiras pelas quais a ligação entre individualismo e movimentos sociais tem sido rotineiramente analisada nas ciências sociais. Em segundo lugar, são sugeridas as formas pelas quais o individualismo e os movimentos sociais devem ser entendidos no contexto da América Latina. Finalmente, e a partir dessa reconsideração, são apresentadas as tensões específicas entre os dois fenômenos sociais na região.
\end{abstract}

Palavras-chave: Individualismo. Movimentos sociais. Ação coletiva. Hiper-ator. Individualismo agêntico.

\section{Introducción}

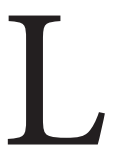

a articulación entre el individualismo y los movimientos sociales es una cuestión ampliamente debatida en las ciencias sociales estadounidenses o europeas, pero notoriamente ausente en el marco de la sociología latinoamericana. Es lo que explica el carácter exploratorio del presente artículo. Para producir este acercamiento procederemos en tres grandes movimientos. En primer lugar, recordaremos brevemente las maneras como el lazo entre individualismo y movimientos sociales ha sido habitualmente analizado en las ciencias sociales. En un segundo momento, subrayaremos las maneras en que se sugiere entender en el marco de América Latina tanto el individualismo como los movimientos sociales. Por último, y a partir de esta reconsideración, presentaremos las tensiones específicas entre ambos fenómenos sociales en la región.

\section{El Individualismo y los Movimientos Sociales}

En las ciencias sociales europeas o estadounidenses, este tema ha sido objeto de un sinnúmero de estudios. Al menos dos grandes modos de abordaje se distinguen claramente.

1. La primera modalidad es consustancial a la noción misma del individualismo. Tanto en Constant (1980) como en Tocqueville (1961), de manera explícita, el individualismo, en estrecho vínculo con el liberalismo, es definido como una filosofía que desplaza el centro de gravedad desde la vida pública (y de la exigencia del compromiso republicano) hacia la vida privada o las actividades del mercado. El burgués triunfa sobre el ciudadano. Desde su primera formulación, el individualismo señala una ruptura con la exigencia de la participación republicana.

Los dos grandes principios del individualismo pueden enunciarse fácilmente. Por un lado, el primado del individuo sobre el colectivo. Éste es sin lugar a duda el punto álgido. En contra de todas las visiones comunitarias u holistas, pero también de la tradición republicana propiamente dicha, el individualismo, en la estela del liberalismo, decreta no solamente el carácter político fundador de la vida humana (desde Hobbes), sino también, y sobre todo, que el colectivo debe estar al servicio de la realización de sus miembros. Por otro lado, como consecuencia de lo anterior, autoriza la sustracción 
de los individuos de la vida pública: cada cual puede, legítimamente, consagrarse a sus negocios o a su vida familiar y amical a distancia de todo compromiso público o político.

Es necesario subrayar la profundidad de la ruptura. El todo, el colectivo, debe estar al servicio de sus miembros, es decir, la vida privada cuenta más que la vida pública y la libertad política debe garantizar sobre todo la libertad individual (DONEGANI; SADOUN, 2007, p. 34). Consecuencia inmediata: la vida personal y el interés exclusivo por ella se instituyen como una dimensión legítima a distancia de todo imperativo de participación política. Tanto en el célebre discurso de Constant de 1819, sobre la diferencia de las libertades entre los Antiguos y los Modernos como en La Democracia en América (1835-1840) de Tocqueville, estos aspectos son visibles y centrales. Puesto que cada individuo es dueño de sí mismo, se impone la necesidad de la no injerencia pública. O sea, para retomar los términos de Berlin (1988), la libertad negativa prima sobre la libertad positiva. Si las dos libertades son necesarias, la negativa (la ausencia de interferencias) y la positiva (el dominio), la primera, la posibilidad de desligarse o de no participar en la vida del colectivo, es la libertad central.

Constant (1980) es explícito: el gobierno debe limitarse a ser justo, los individuos se ocuparán ellos mismos de ser felices. Mientras más tiempo tengan estos para dedicarse a sus intereses privados, más valiosa les será la libertad. Sin embargo, Constant es consciente del hecho que, el individuo absorbido por sus preocupaciones personales (por su pequeña sociedad, dice Tocqueville) y alejado de los asuntos públicos (la gran sociedad, precisa Tocqueville), esta situación puede derivar hacia la tiranía. La conclusión es clara en ambos autores: a pesar del primado de la libertad negativa es preciso aprender a combinar (el verbo es de Constant) las dos libertades. Nada de extraño por ende si para un liberal socialista como John Stuart Mill el voto debía ser no solamente obligatorio sino también público, ello como una manera de dar pruebas al colectivo de su compromiso con él.

Desde entonces, la tensión entre los dos fenómenos, el individualismo (y la tentación de la reclusión en la vida privada) y la participación política, no han cesado de ser un problema señero en las ciencias sociales.

2. Más o menos en continuidad con las reflexiones de Constant o de Tocqueville, las ciencias sociales no han dejado de preguntarse por las razones que podrían motivar o desincentivar a los individuos a participar en los asuntos públicos.

En este marco, la problemática más importante concierne a las razones por las que un actor individualista, animado antes que nada por la prosecución de sus intereses personales, acepta participar en una acción colectiva. Leída desde el individualismo, la acción colectiva es una paradoja. Nadie tiene individualmente interés en participar (o sea en asumir el costo personal que ello implica); cada cual tiene interés en que la acción colectiva sea realizada por otros (para beneficiarse, así, sin costos individuales de sus resultados, esto es, la lógica del free rider). Enunciada con toda la contundencia necesaria por Olson (1978), la tesis no ha dejado desde entonces de producir una importante literatura académica en la que cada nueva proposición ha tratado de explicar desde las coordenadas del individualismo lo inexplicable, o sea, la existencia de acciones colectivas.

No es posible aquí hacer una presentación exhaustiva, pero se pueden indicar, entre otras razones explicativas dadas a esta cuestión, la idea del mismo Olson de la existencia de mecanismos organizacionales coercitivos, que obligan a la participación (como la ley de la sindicalización obligatoria que limita los riesgos del free rider); la proposición de Oberschall (1973) en torno a los mayores riesgos, pero también, y a causa de ello, a los mayores beneficios que obtienen los líderes; la idea de Pizzorno (1991) según la cual el cálculo costo-beneficio se hace desde identificaciones colectivas y no a partir de intereses exclusivamente personales; o la tesis de Hirschman (1983) sobre la 
existencia de ciclos en donde se alternan momentos de búsqueda de la felicidad privada y momentos de anhelos de participación y excitación pública. Vale la pena indicar también, desde un enfoque complementario, los trabajos que, desde la perspectiva de la movilización de recursos, desde fines de los años 1970, subrayan los diferenciales de costos y oportunidades de movilización que facilitan, o no, la acción colectiva.

De este muy breve recorrido, resulta indispensable retener una problemática central: en el marco de las ciencias sociales, en este punto sobre todo estadounidenses más que europeas, el individualismo y la idea de actores animados por una lógica costo-beneficio (desde el individualismo metodológico hasta el rational choice), transforma, desde su origen, toda acción colectiva en un problema. Por un camino completamente distinto se llega o se refuerza la constatación normativa fundamental del individualismo: a saber, la existencia de individuos legítimamente dedicados a la prosecución de sus intereses personales.

\section{La Situación Latinoamericana}

Tanto la debilidad histórica del tema del individualismo en América Latina como la relativa marginalidad en la sociología de la región del paradigma del rational choice han hecho que la problematización entre el individualismo y la acción colectiva haya sido poco abordada. Sin embargo, como lo veremos, la cuestión también se plantea en la región, pero lo hace a partir de una especificidad: por medio de la tensión que se estructura entre movimientos sociales débiles y actores individuales fuertes. Explicitemos el sentido de esta doble caracterización.

\section{Movimientos Sociales Débiles}

Si las ciencias sociales han propuesto lecturas disímiles de los movimientos sociales en América Latina, es posible, sin embargo, afirmar que una problemática es recurrente en ellas: la idea de una larga tradición de subordinación de los actores sociales al sistema político. Como a propósito del individualismo, como lo veremos en un momento, el análisis es inseparable de un cierto juicio de valor. La existencia de una sociedad civil dinámica y sólida en Europa, de una tradición de luchas sociales autónomas con respecto al Estado, o de una larga tradición de asociaciones y de benévolos en los Estados Unidos han servido como marco de comparación para señalar las insuficiencias en América Latina. Una lectura que, digámoslo de paso, minimiza la muy fuerte articulación entre sindicatos y partidos políticos en la socialdemocracia y sus tendencias corporativas.

En cualquier caso, los movimientos sociales en la región son caracterizados como poseyendo una débil autonomía con respecto al sistema político. La afirmación, por supuesto, se matiza en función de periodos y de países, pero no por ello es menos común a todos los grandes movimientos sociales latinoamericanos (sindicatos obreros o campesinos, movimientos urbanos, luchas feministas, movimientos indigenistas, luchas estudiantiles, movimientos ecologistas). La situación fue extrema, tanto en los regímenes nacional-populares de las décadas 1940 a 1960 como en sus variantes más recientes, en donde la debilidad organizacional de los actores colectivos es reforzada por formas corporativas, principios asistencialistas o lógicas clientelares altamente dependientes del sistema político. Para Touraine (1988) este peculiar modo de articulación entre actores sociales, sistema 
político y Estado habría caracterizado durante largo tiempo lo propio de la situación latinoamericana. Lo esencial: la característica mayor de este modelo es la subordinación de los actores sociales al sistema político y del sistema político al líder.

Esta subordinación es visible en los lazos estrechos y dependientes que tienen con el aparato estatal o los partidos políticos (algo particularmente visible en las alianzas políticas, más o menos durables, entre movimientos obreros, movilizaciones indígenas, estudiantiles o feministas con ciertos partidos). Una subordinación tanto mayor cuanto que desde el poder no cesan de desarrollarse estrategias de presión, de cooptación o de represión contra los actores sociales con pretensiones de autonomía.

Las razones para dar cuenta de esta subordinación estructural de los actores sociales al sistema políticos han sido diversas, pero dos de ellas son recurrentes. Por un lado, desde Germani (1962) se indica la debilidad de la conciencia de clase entre los sectores populares en la región. Por otro lado, se tiende a subrayar las condiciones materiales y la extrema pobreza de los sectores populares, lo que facilitaría estructuralmente la construcción de lazos clientelares entre el Estado, la administración y los actores sociales (AUYERO, 2013). Por supuesto, dentro de este marco general, las relaciones con los partidos políticos y el Estado son disímiles según que los actores sociales privilegien estrategias negociadoras, de participación ciudadana, combativas o clasistas. Pero, a pesar de ello es posible reconocer en la larga duración la realidad de actores sociales subordinados al sistema político.

Es en este marco en el que deben entenderse las tensiones introducidas hace unas décadas por las ONG y más ampliamente por la sociedad civil. Recordemos que estas asociaciones nacen en América Latina en los años 1970, en una época de movilización social y política que se desarrolla en el contexto autoritario de las dictaduras militares, período en el cual, a raíz de la restricción de la escena político-partidaria, pasaron a ocupar un lugar de importancia como actores sociales. Ello tanto más que las ONG contaban con un importante financiamiento internacional, lo que les permitió mantener una cierta autonomía con respecto al Estado. Tras varias décadas de presencia, el destino diverso de las ONG y de otras manifestaciones de la sociedad civil es una prueba suplementaria de la debilidad de los actores sociales en la región. O bien muchas de ellas terminaron siendo aspiradas por partidos políticos (y las gestiones municipales) o bien muchos de sus miembros desarrollaron un discurso fuertemente crítico hacia la ciudadanía. Para muchos militantes de las ONG, en acuerdo con una filosofía que propulsa el desarrollo de una ciudadanía activa, los actores sociales eran "resistentes" a desarrollar acciones verdaderamente autónomas, presos o de la desmoralización o de una tradición clientelista (MARTUCCELLI; SVAMPA, 1997).

El diagnóstico sobre la debilidad de los movimientos sociales en la región es todavía más patente en los últimos años. Detrás de la reorientación económica y política de las últimas décadas, es la naturaleza misma de los sindicatos la que es cuestionada y su rol de agentes mixtos de co-regulación pública y de contestación colectiva (SORJ; MARTUCCELLI, 2008). Cautivos en medio de una inversión global de las relaciones de fuerza entre el capital y el trabajo (y la consolidación y expansión del sector informal) o enfrentados a nuevas tecnocracias públicas fuertemente reticentes a ellos y a la aparición de liderazgos políticos (como Menem o Fujimori) que desmantelaron el antiguo poder sindical o rompieron con él a fin de imponer el suyo, los sindicatos encuentran difícil redefinir su nuevo rol. A lo anterior se añade el declive de ciertas formas de participación política y social juzgadas tradicionales, así como la emergencia de un nuevo perfil de activista, en donde el equilibrio entre lo público y lo privado se busca desde nuevas bases, donde el objetivo de la participación también se lee desde la experiencia personal, y en el cual, sobre todo, se reconoce lo bien fundado de una 
necesaria división de los dominios de la vida individual. También entre los militantes la vida privada (y el individualismo) gana peso.

Lo esencial: en una visión sintética de larga duración, la debilidad organizacional y la heteronomía aparecen como una de las características centrales de los movimientos sociales en América Latina.

\section{Actores Individuales Fuertes}

El individualismo, la legitimidad de una vida personal a distancia de toda implicación pública, fue en Europa y en parte en los Estados Unidos inseparable de un conjunto de interpelaciones institucionales y de políticas sociales. La teoría social, con razón, ha denominado esta realidad como el individualismo institucional. En este marco se da mucha importancia a los dispositivos que interpelan a los individuos para que se constituyan en sujetos (desde el mercado hasta la ciudadanía, pasando por la escuela o los sentimientos) y a las políticas sociales (derechos, servicios públicos, gubernamentalidad) que lo hacen posible. En este punto la coincidencia analítica es profunda entre Durkheim y Weber, Parsons y Bourdieu, Elias y Foucault, Althusser y Touraine. En estas sociedades el individualismo es indisociable de fuertes procesos de institucionalización.

La situación en América Latina es diferente. Si tanto las instituciones como las políticas sociales son importantes, la experiencia de los individuos y sobre todo la percepción colectiva son distintas. Lo que prima es la idea de individuos que deben constantemente hacer frente, muy solos, a imprevistos y desafíos tanto macro-sociológicos (inflaciones, inestabilidades políticas, cambios ligados a la globalización, entre otros) como microsociológicos (despidos, evoluciones familiares, problemas de salud y más) (MARTUCCELLI, 2010). Se podría argüir, con razón, que éste es un hecho transversal a muchas sino a todas las sociedades. Cierto. Pero lo importante es reconocer que detrás de la aparente similitud de estas situaciones, es en los modos de enfrentarlas propios a cada sociedad en los que se perfilan las variantes del individualismo. A pesar del peso que la representación del individuo tiene en la trama institucional en América Latina (algo bien reflejado a nivel del derecho), el individuo en la región no se percibe, ni es percibido, como asistido por las instituciones (ROBLES, 2000).

Vale la pena ser explícitos. Incluso cuando, como lo indica Beck (1998), los individuos en las sociedades europeas deben dar soluciones biográficas a contradicciones sistémicas, esto no debe hacer olvidar que las soluciones personales en cuestión son siempre una respuesta inducida por una prescripción institucional. El individualismo es distinto en América Latina. El individuo se siente desprotegido en la sociedad. Se percibe en medio de un combate en el cual se ve obligado a estar siempre vigilante y al acecho, compelido a ser un actor en el sentido más fuerte del término. La cuestión del individualismo no gira así esencialmente en torno a la elección y al cálculo racional, sino que aparece como una cuestión existencial: el individuo para poder ser un individuo tiene que desplegar un conjunto particular de habilidades prácticas. El individualismo en América Latina remite antes que nada a la realidad de individuos que son híper-actores (ARAUJO; MARTUCCELLI, 2014).

En la región el individualismo es inseparable de un individuo que tiene por sobre cualquier cosa que "arreglárselas". Dado el rol particular de las instituciones, el individuo está obligado a enfrentar diversas contingencias de manera profundamente personal, incluso cuando recurre a ciertos recursos institucionales, solidaridades o redes grupales. Los individuos se conciben como lidiando y existiendo, 
por sí mismos y gracias a sus propias facultades, en medio de una sociedad percibida como altamente adversa. Nada lo muestra mejor que el fuerte contraste observable, a nivel de estos dos individualismos a la hora de comparar los efectos de la precariedad laboral sobre los individuos. Ahí donde, desde el individualismo institucional se subrayan sobre todo nuevas formas de sujeción y experiencias de exclusión social o de destrucción subjetiva (CASTEL, 1995; SENNETT, 2000), en América Latina, sin que esta realidad sea desconocida, los estudios subrayan otras dimensiones (RAMOS, 2009) y el trabajo informal es leído como una fuente compleja de producción de individualidades (MATOS MAR, 1984; DE SOTO, 1986; LAVÍN, 1987). A diferencia de los discursos críticos enunciados desde el individualismo institucional, en el individualismo, agentico, la ausencia de apoyo institucional no justifica ningún fracaso.

El individualismo en América Latina es la filosofía de un híper-actor relacional, esto es, se trata de un individualismo agentico (ARAUJO; MARTUCCELLI, 2012, 2014; MARTUCCELLI, 2015). Ésta es la tradición del individualismo en la región. El individuo debe sobreponerse, gracias a su habilidad, su esfuerzo y sus relaciones, a las situaciones. Ser hábil es por sobre todo ser capaz de aprovechar las oportunidades. En sociedades en donde tantas veces se hace la doble experiencia contradictoria, por un lado, de que todo está bloqueado y, por el otro, de que las posiciones sociales son inconsistentes e inestables, la oportunidad es un correlato natural del individuo hábil. Tras ella se diseña la figura particular de un individuo que posee una forma de inteligencia que combina la sagacidad, la prudencia, la osadía, el olfato, la vigilancia, el amague, lo que, en breve y para decirlo con una expresión típicamente latinoamericana, exige tener cintura. Lo importante es saber sortear obstáculos. Una actitud que, aun cuando esté presente en todas las categorías sociales, es particularmente visible entre los sectores populares (MERKLEN, 2004; ARAUJO; MARTUCCELLI, 2015).

Sin embargo, a pesar de esta omnipresencia, la habilidad para aprovechar la oportunidad no es el resultado de una prescripción institucional. Por el contrario, el individualismo agentico no cesa de pensarse en tensión con las instituciones. En este contexto se entiende muchas veces que ser individualista supone desarrollar actitudes anti-colectivas y anti-institucionales. Resulta indispensable subrayar esta tensión. El oportunismo, cuya realización es por lo general exclusivamente individual, es un auténtico valor colectivo. Sin duda ambivalente, pero un valor colectivo. La astucia individual es profundamente jubilatoria y una fuente de admiración tanto para sí mismo como para los otros, incluso cuando se sospecha de su ineficacia a mediano plazo. En ello se diferencia de la transgresión de la ley, la que aun cuando a veces es percibida como una manifestación de poderío personal y de impotencia colectiva, al ser inseparable del abuso, genera tarde o temprano rechazo (MENDEZ et al., 2002; NINO, 2005; GIROLA, 2005; ARAUJO, 2009). El oportunismo puede ser a veces considerado un vicio colectivo, pero es muchas veces representado si no como una virtud personal al menos como una indispensable habilidad individual.

El individuo se concibe y se enuncia subrayando sus capacidades de híper-actor: el conjunto de competencias adquiridas y necesarias para desenvolverse en la vida social. De este modo, es desde las vicisitudes del lazo social más que desde los programas institucionales como los individuos construyen su individualidad. Estas capacidades se materializan en dos polos, por un lado, en una fuerte afirmación de sí en torno al esfuerzo y la habilidad (SOUZA, 2012), por el otro, en la capacidad a movilizar o tejer relaciones. El individualismo agentico oscila, así, entre un discurso abiertamente heroico sobre sí mismo y el reconocimiento subrepticio del sostén recibido por parte de ciertas personas o redes. Esta dualidad distingue por lo demás de manera inequívoca el individualismo agentico del modelo del Self Made Man. El individuo es un híper-actor relacional. La evocación permanente de la 
confianza en sí mismo obtiene su plena significación sociológica si se la entiende como el combustible indispensable que es preciso poseer para enfrentar los retos cotidianos. Esta actitud permite, por ejemplo, a muchos individuos, poder sentir (o al menos decir) que, si su situación económica se deteriorara en exceso, encontrarían empero en ellos, y en un círculo estrecho de relaciones, la fuerza necesaria para salir adelante. Aquí reside la especificidad del individualismo latinoamericano y de sus actores fuertes.

\section{Tres Problematizaciones}

¿Cómo se plantea en el marco de las sociedades latinoamericanas el lazo entre el individualismo y los movimientos sociales? O para decirlo en los términos que se desprenden del apartado precedente, ¿qué se produce en el choque entre hiper-actores individuales fuertes y movimientos sociales débiles?

Para permanecer en los límites de extensión de este artículo y respetar su dimensión exploratoria, nos limitaremos a abordar tres puntos. Primero, la manera cómo se plantea en este contexto la cuestión de la participación o no en la acción colectiva. Segundo, las maneras en que se traduce la cuestión de lazo entre vida personal y participación política. Tercero, las consecuencias que a nivel de las organizaciones colectivas producen las individualidades fuertes. Notemos que, si las dos primeras temáticas se vinculan con las dos grandes preguntas que las ciencias sociales han tradicionalmente formulado a propósito de los lazos entre acción colectiva e individualismo, el tercer punto es altamente especifico a la región.

\section{El Individuo Híper-actor y la Cuestión de la Participación Política}

La cuestión retrotrae a la pregunta por las razones por las que un individuo decide, o no, participar a una acción colectiva. Más allá de los debates alrededor de la tesis del rational choice, en América Latina el problema se plantea en otros términos: la acción colectiva no es la principal vía de solución de problemas escogida por los individuos.

Los individuos híper-actores optan, las más de las veces, por resolver, a su nivel y con sus propias capacidades, los desafíos de la vida social. La desconfianza hacia los actores instituidos ( indicatos, ONG), pero también a la ley como marco de regulación de las relaciones sociales, a lo cual se añade en las últimas décadas un innegable empoderamiento de los actores individuales, hacen que la acción colectiva pierda atractivo.

Es importante comprender esta problemática en su filiación histórica. El incremento de expectativas no implica necesariamente una traducción política. Esto puede llevar a formas que canalizan o traducen las inquietudes y expectativas individuales en universos de sentido construidos al margen del sistema político (la ilegalidad o la emigración). La tesis de que las democracias en los países en desarrollo son desbordadas por el exceso de demandas sociales sólo se aplica en los casos en que estas demandas encuentran canales político-ideológicos capaces de presionar y colocar en jaque al sistema político. Si esta situación no es en absoluto extraña a América Latina hoy en día, lo que se ha afirmado cada vez más es la presencia de actores individuales que poseen nuevos e inéditos márgenes de iniciativas personales.

Sombart (1992) interpretó la ausencia del socialismo en Estados Unidos como una consecuencia de la fuerza del imaginario de la frontera. Los actores elegían estrategias de exit antes que de voice. Algo análogo se produce hoy en América Latina. A pesar de la permanencia de importantes 
desigualdades sociales, los individuos tienden a canalizar sus exigencias crecientes de realización personal menos a través de demandas colectivas de justicia o demandas directas al sistema político que dirigiéndose hacia el mundo privado, al consumo, la violencia, la emigración o con estrategias individuales de construcción de sentido y de sobrevivencia (PÉREZ SÁINZ, 2019).

La emigración es un buen ejemplo de esta realidad. Si su peso es muy distinto entre los países y las razones migratorias son muy distintas (económicas, políticas, colectivas e individuales), en todos los casos constituye una apertura del horizonte de lo posible. Cuando no parece factible, o rentable, reivindicar derechos (voice) queda la oportunidad de irse (exit): una suerte de versión latinoamericana de la frontera. Esta aventura, que la región ya vivió en los procesos de salida del campo hacia la ciudad, ahora se da en escala internacional. Si la aventura no es exitosa para todos, ello no impide que el imaginario de la migración erosione las jerarquías y la resignación. El ejemplo es tanto más interesante cuanto que detrás de su aparente individualismo, la migración y la emigración son indisociables de un conjunto de recursos colectivos y muchas veces aparece, gracias a las redes migratorias, como otra manera de afirmar la pertenencia a un colectivo étnico o regional. Pero la instauración de la emigración en el imaginario abre una válvula de salida que a su manera desalienta la movilización y la participación colectiva.

No se trata por supuesto de oponer los individuos a los movimientos sociales, pero sí de comprender el rol, muchas veces ambiguo, que el indudable incremento de las iniciativas individuales introduce en la participación colectiva. Si durante mucho tiempo se pensó que el aumento de las expectativas conducía inexorablemente a un desborde político, hoy por hoy es preciso reconocer el abanico más amplio de respuestas que los actores, de manera colectiva o individual, encuentran a los problemas sociales.

Esta inflexión es particularmente visible en la consolidación de un importante sector informal en muchos países latinoamericanos. Resulta imposible desconocer los elementos de crisis que subyacen en esta "solución", pero es importante reconocer también que su constitución permitió, y permite, una gestión individualizada de la insuficiencia en términos de empleo, (MARTUCCELLI, 2015). Para comprenderlo puede ser útil leer el sector informal desde lo que Bayat (2013) ha denominado como un "no movimiento social". Una lógica de acción por agregación numérica de acciones individuales sin objetivo político explícito que permite, empero, que los actores sociales modifiquen su entorno colectivo. Gracias a los "nonmovements", a través de la invasión, la usurpación o el desborde institucional, los individuos, escasamente organizados, transforman desde abajo la sociedad. Bayat precisa su caracterización: se trata de acciones orientadas (intencionalmente efectuadas) pero que no son ideológicamente construidas; son realizadas más por individuos que por colectivos; no son acciones extraordinarias sino ordinarias; se trata de prácticas comunes realizadas todos los días y altamente fragmentadas. La idea no es en sí misma nueva, y debe ser puesta en relación con una amplia familia de acciones que muestran justamente las capacidades de transformación ordinaria, desde abajo de la sociedad, por los individuos. Sin embargo, si la traemos a colación es porque para Bayat los actores del sector informal (subterráneos, aunque visibles) están desprovistos de toda vocación política. No se trata, así, de una "acción colectiva individualizada" (MICHELETTI, 2013) en la cual, como en el caso del consumo, los individuos articulan, con conciencia política, aspectos colectivos e individuales. En el caso de los "no movimientos" los individuos oscilan entre pasividad, estrategias de sobrevivencia, movimientos territoriales urbanos o resistencia cotidiana sin que el análisis pueda, o deba, privilegiar uno de ellos en detrimento de los otros. El autor prefiere hablar de una articulación entre largas y prolongadas movilizaciones atomizadas y episódicos períodos de acción colectiva. La forma de la acción es sigilosa, individual y gradual. 
Lo esencial es que estas acciones no pueden ser abordadas solamente (y aún menos esencialmente) en términos políticos. La principal limitación de los estudios sobre la life politics es justamente la voluntad de leer estas formas de movilización, altamente individualizadas, desde las categorías de la política y a la luz de su posible traducción en términos de acción colectiva organizada. Las acciones individuales tienden a ser leídas en términos de una lucha política contra el sistema, el mercantilismo estatal, el mercado o el abuso. Estas lecturas no solo traicionan el sentido de estas experiencias sociales, sino que transforman toda la vida social y personal en un apéndice de la política. El individuo híper-actor es, así, o bien criticado por su "individualismo" sin horizontes o bien transformado en vanguardia de una lucha colectiva. Estas interpretaciones son a veces justas -cuando efectivamente, pero solo de manera episódica, el actor individual transita hacia una acción colectiva-, pero tienden a desconocer lo que es la principal forma de acción en colectivo y a distancia de toda expresión política de tantos híper-actores individuales.

En breve, si el individuo híper-actor no participa sino esporádicamente en acciones colectivas, ello se debe menos a su inclinación calculadora que a su desconfianza hacia las instituciones y colectivos, y a la confianza inusitada que ha desarrollado en sus capacidades por resolver, a su nivel, los desafíos de la vida social.

\section{El Individuo Híper-actor y la Cuestión de la Vida Privada}

Como lo hemos recordado, Constant contrapone la vida privada y la vida pública. Como para todo buen burgués de comienzos del siglo XIX, la política y sobre todo la movilización popular le asustan. Lo hacen al punto de llevarlo a oponer y defender el bonheur privado a distancia de toda injerencia política. Esta actitud es rastreable en ciertos sectores sociales en América Latina, por cierto, pero en este apartado quisiéramos evocar un caso de figura a la vez más específico y significativo para la región. Para muchos actores sociales, el bonheur de la vida privada no preexiste a la acción colectiva, por el contrario, éste tiende a ser el objetivo de la acción colectiva. O sea, el individuo se moviliza en una acción colectiva para poder ser un individuo desmovilizado (en torno al bonheur privado). Se trata de una dimensión que no siempre es reconocida pero que permite comprender la fuerte presencia, en un gran número de acciones colectivas, de mujeres de sectores populares cuando éste es, implícita o explícitamente, el objetivo principal de la movilización. Vale la pena insistir: los individuos solicitan derechos o bienes públicos a la política, pero el horizonte último es poder sustraerse a la política y poder llevar una vida considerada como normal (acceso al agua, la electricidad, la seguridad). El horizonte es poder participar del estilo de vida de las clases medias (del bonheur del burgués).

Se trata de un tipo de acción particularmente visible en los movimientos sociales barriales. Frente a la carencia de los servicios públicos, los actores se organizan, a veces con la ayuda de grupos religiosos, ONG o partidos políticos, para poder responder a estas demandas no satisfechas. Son movilizaciones que, sobre todo en los países con menor infraestructura estatal, a la vez que legitiman parcialmente la acción colectiva, deslegitiman la acción gubernamental. El resultado es, así, muchas veces un incremento de las iniciativas de muchos actores. Pero este proceso al realizarse por otros canales que la acción gubernamental, y muchas veces como crítica explícita hacia las insuficiencias de ésta, agudiza la desconfianza hacia el Estado. En todo caso, como en muchos otros lugares (DAVIS, 2006), la situación de pobreza hace que en muchos de estos habitantes se observen actitudes contrarias, a la vez de solidaridad y de crisis, de ayuda mutua y de recelo, de autonomía y de dependencia. El carácter episódico o urgente de las movilizaciones colectivas prima sobre toda lógica de acción durable. A veces resulta difícil hablar de acción colectiva, a tal punto la vida individual oscila entre períodos de organización puntual y fases de apatía o desmovilización. 
Ésta es una situación que se agudiza en los barrios más marginados en donde las capacidades colectivas de acción son escasas y los márgenes reales de autonomía precarios (CARDOSO, 1983).

Pero si a propósito de la desmoralización de los actores sociales más vulnerables la literatura académica es abundante, las interpretaciones han tendido a desconocer otro aspecto. A saber, que en el corazón de muchas de estas acciones colectivas se encuentra la voluntad de sustraer (a veces de construir) el ámbito privado a distancia de la política (MARTUCCELLI; SVAMPA, 1997). La "totalidad" de la experiencia de vida de los sectores populares más vulnerables se desenvuelve inundada por lo político. Por supuesto, los barrios populares, en América Latina, son a todas luces lo opuesto de una situación totalitaria, pues la vida social se encuentra por lo general abandonada por la intervención estatal. Sin embargo, en una situación de este tipo se produce una profunda politización de la vida cotidiana. En una situación de miseria extrema o aguda, el conjunto de la vida social se vuelve un terreno de reivindicación (agua, luz, títulos, transportes, seguridad, trabajo, educación, salud). La vida privada está penetrada por lo político. Un buen número de prácticas sociales testimonian u obligan a una reivindicación política. Para los habitantes de los barrios periféricos urbanos hay un vaivén incontrolable entre lo político y la cotidianidad. La política (politics) está presente, gracias a la ausencia de las políticas (policies), en un gran número de actividades cotidianas. Coinciden así, más que se oponen, la desafección política de los habitantes y la politización extrema de la vida cotidiana.

En este marco, no es de sorprenderse que uno de los objetivos de la reivindicación colectiva sea lograr una separación entre los dos ámbitos sociales. La movilización debe entenderse menos como el paso de lo privado a lo público o como una politización de lo privado y más como la voluntad de establecer, gracias a la acción colectiva, la separación real entre los dos dominios. A lo que se aspira es a sustraer la vida cotidiana de la política; a trazar una frontera que permita vivir una vida personal. Lo que se busca es poder gozar de una esfera privada, como lo testimonia el con frecuencia rápido declive de la acción colectiva cuando los principales elementos de la vida privada (infraestructura, seguridad) han sido conseguidos. La demanda de infraestructuras públicas a través de movilizaciones colectivas más o menos esporádicas apunta a satisfacer demandas individuales.

Desde América Latina, por ende, uno de los grandes principios del individualismo, la legitimidad y el anhelo de una vida privada a distancia de la participación política, invita a una interpretación peculiar de ciertas formas de acción colectiva. Lo importante es comprender que la movilización, cuando se produce, apunta, como anhelo, a producir las condiciones de la desmovilización.

En breve, el burgués, en el análisis de Constant, defiende el ámbito privado de la injerencia política. En ciertos contextos en América Latina, la situación es distinta: la acción colectiva con frecuencia se hace con el fin, más o menos explícito, de construir un dominio privado. El individuo híper-actor participa en una acción colectiva para incrementar su margen posible de bonheur individual.

\section{El Individuo Hiper-actor y la Canibalización de los Movimientos Sociales}

La tercera problematización del lazo entre individualismo y acción colectiva es aún más específica de la región y resulta del choque directo entre individuos fuertes y movimientos sociales débiles. Por supuesto, el problema de individuos que buscan beneficios personales a través de acciones colectivas o el de la usurpación del poder por los líderes de la organización (MICHELS, 1971) no es una exclusividad latinoamericana, pero aquí toma ribetes excesivos. A falta de espacio, revisemos solo algunos grandes casos de figura.

La primera figura concierne al líder (los jefes). Su peso y su función en la región son una evidencia. Desde las Repúblicas hispanoamericanas post-independencia en el siglo XIX (los caudillos) hasta los incluso 
muy poco carismáticos jefes políticos de los últimos lustros pasando por los grandes líderes de los regímenes o movimientos nacional-populares de mediados del siglo XX, las grandes figuras del individuo híper-actor (el líder) canibalizan los movimientos sociales en su interés propio. En el acto político central del nacionalpopulismo, el encuentro del líder con el pueblo en la plaza, el Jefe es el verdadero actor: él es quien interpela al Pueblo que debe permanecer en clara situación de subordinación (MARTUCCELLI; SVAMPA, 1997). Ciertamente, la relación es inestable y es absurdo negar todo protagonismo a los actores sociales, pero su rol muchas veces se define y circunscribe por los intereses del líder.

La segunda figura es más ordinaria. Una frase de ingenio popular la resume a cabalidad: el Jefe es aquel que sabe sacrificar el interés general al interés particular. Dentro de una organización, el individuo híper-actor continúa desarrollando y haciendo uso de sus habilidades personales, de sus estrategias de connivencia, convivialidad, astucia, trampa, criolladas, tácticas. El abuso frecuentemente forma parte de estas capacidades, puesto que, para evocar otra frase popular, autoridad que no abusa se desacredita (ARAUJO, 2016). Cada líder, a su nivel de acción y responsabilidad, tiende a constituir en torno a él un ámbito de poder más o menos discrecional. En el caso del sindicalismo, ello fue muchas veces de índole burocrático gracias a un estrecho vínculo de los dirigentes con las instancias estatales, lo cual, a su vez, al alejarlo de la base obrera, provocó sistemáticamente desconfianza hacia los liderazgos y recurrentes demandas de democratización (ZAPATA, 1993). Otras veces, como en tantas ONG, el proyecto colectivo está altamente supeditado a la existencia de animadores, verdaderos híper-actores individuales, sin cuya presencia y energía la acción colectiva desaparece, pero que, al mismo tiempo, asocian la fortuna de ésta al interés personal. Las diferencias son notorias, pero la necesidad de preservar el poder discrecional de los Jefes da cuenta, a su manera, de la muy débil institucionalización de los movimientos sociales y sobre todo de los partidos políticos en la región.

Finalmente, la tercera figura, de índole más crítica, permite comprender dentro de este marco la fuerza del tema de la corrupción en la región desde hace varias décadas. Detrás del combate contra ella, común a tantos otros países en el mundo, es preciso reconocer una especificidad. La corrupción y el nepotismo son en la región inmediatamente comprendidos como la manifestación, en el ámbito público, de las maneras habituales de operar en la vida social de individuos híper-actores, acostumbrados a actuar a través de un uso privativo de los privilegios y en beneficio exclusivo de algunos (corporaciones, argollas, redes, compadrazgos). El fenómeno no es ni nuevo ni exclusivo de América Latina. Pero en otros lares se lo juzga y percibe como una desviación personal, y en otros periodos en la región se lo percibió como una fatalidad en medio de débiles aspiraciones meritocráticas. Las dos dimensiones se superponen hoy en día. La canibalización de la acción colectiva por intereses privados no se interpreta solamente como una cuestión de personas sino como la expresión de un modo perverso de agencia individualista que es tanto más insoportable cuanto que la meritocracia o al menos un fuerte anhelo de ascenso social tienden a convertirse en ideales colectivos. La tensión es mayúscula así entre, por un lado, lo que los individuos híper-actores hacen y no dejan de hacer en el ordinario de sus vidas, y lo que, por otro lado, quisieran que sus líderes hagan por el interés colectivo (lo que da cuenta del interés creciente por la tradición republicana y un individualismo más moral en la región).

Las figuras que hemos evocado rápidamente son diferentes entre sí, pero en cada una de ellas, a través de mecanismos distintos, los movimientos sociales y los partidos políticos son canibalizados por los líderes. Los diferentes jefes, cada uno en función de su radio de acción, no solamente obtiene beneficios materiales y simbólicos diferenciales de su participación en la acción colectiva (un factor común en todas las latitudes), sino que, más o menos subrepticiamente, tiende a subordinar la acción colectiva y el interés general a sus designios personales. La longeva debilidad estructural de los movimientos sociales en América Latina es, no solo pero también, una consecuencia de la no menos longeva fortaleza de sus individuos hiper-actores. 


\section{Consideraciones Finales}

Las reflexiones exploratorias desarrolladas en este articulo no solo no son exhaustivas, sino que, dada las limitaciones de espacio, no hacen justicia a la gran diversidad de movilizaciones colectivas en América Latina, muchas de ellas irreductibles a la problemática abordada en este artículo. Sin ser una excusa, vale la pena, no obstante recordar que ello es común al ejercicio de análisis sociológico: también en las ciencias sociales estadounidenses o europeas el vínculo entre el individualismo y la acción colectiva no agota, ni pretende hacerlo, el estudio de los movimientos sociales. De lo que se trata, y de lo que se ha tratado en este artículo es de presentar un conjunto específico de problematizaciones alrededor de esta temática.

No obstante, más allá de la cuestión específica de la acción colectiva una conclusión de índole más general se desprende de nuestro análisis. El individualismo agentico define una filosofía política sui generis. A diferencia del liberalismo y su confianza en las leyes y la arquitectura constitucional; de la tradición republicana y su confianza en la virtud de los ciudadanos y gobernantes; o del socialismo y su confianza en la movilización popular, el individualismo agentico no deposita su confianza ni en las instituciones ni en la probidad ciudadana como tampoco en la movilización colectiva. En rigor, se podría decir que no deposita su confianza en ninguna ley o actor, sino que la conserva para sí misma. Su confianza va antes que nada en dirección de las capacidades que cada cual sabe o piensa poseer por sí mismo. Es desde esta realidad social, contando con ella y contra ella, que se construyen las instituciones y las acciones colectivas en América Latina.

\section{Contribuición de los Autores}

Conceptualización de la investigación, Araujo K y Martuccelli D; Revisión de la literatura, Araujo K y Martuccelli D; Instrumentos de recolección y análisis de dados, Araujo K y Martuccelli D; Discusión, Araujo K y Martuccelli D; Escritura, Araujo K y Martuccelli D; Corrección de estilo, Araujo K y Martuccelli D.

\section{Referencias}

ARAUJO, K. Habitar lo social. Santiago: LOM Editores, 2009.

ARAUJO, K. El miedo a los subordinados. Santiago: LOM Ediciones, 2016.

ARAUJO, K.; MARTUCCELLI, D. Desafíos comunes. Santiago: LOM Ediciones, 2012. 2 tomos.

ARAUJO, K.; MARTUCCELlI, D. Beyond institutional individualism. Agentic individualism and individuation process in Chilean society. Current Sociology, v. 62, n. 1, p. 24-40, jan. 2014. https://doi. org/10.1177/0011392113512496

ARAUJO, K.; MARTUCCELLI, D. Las individualidades populares. Análisis de sectores urbanos en Chile. Latin American Research Review, v. 50, n. 2, p. 86-106, summer, 2015. https://doi.org/10.1353/lar.2015.0022

AUYERO, J. Pacientes del Estado. Buenos Aires, Eudeba, 2013.

BAYAT, A. Life as politics. Stanford: Stanford California Press, 2013.

BECK, U. La sociedad del riesgo. Barcelona: Paidós, 1998. 
BERLIN, I. Eloge de la liberté. Paris: Calmann-Lévy, 1988.

CARDOSO, R. Movimentos sociais urbanos: Balanço critico. In: SORJ, B.; TAVARES DE ALMEIDA M. H. (eds.). Sociedade e política no Brasil pós-64. São Paulo: Editora Brasiliense, 1983.

CASTEL, R. Métamorphoses de la question sociale. Paris: Fayard, 1995.

CONSTANT, B. De la liberté chez les Modernes. Paris: Hachette, 1980.

DAVIS, M. Planet of slums. London: Verso, 2006.

DE SOTO, H. El otro sendero. Lima: Editorial El Barranco, 1987.

DONEGANI, J.-M.; SADOUN, M. Qu'est-ce que la politique? Paris: Gallimard, 2007.

GERMANI, G. Política y sociedad en una época de transición. Buenos Aires: Paidós, 1962.

GIROLA, L. Anomia e individualismo. Madrid: Anthropos-UAM, 2005.

HIRSCHMAN, A. O. Bonheur privé, action publique. Paris: Fayard, 1983.

LAVÍN, J. Chile: La revolución silenciosa. Santiago: Editora Zig Zag, 1987.

MARTUCCELLI, D. ¿Existen individuos en el Sur? Santiago: LOM Ediciones, 2010.

MARTUCCELLI, D. Lima y sus arenas. Limas: Cauces editores, 2015.

MARTUCCELLI, D.; SVAMPA, M. La plaza vacía. Buenos Aires: Losada, 1997.

MATOS MAR, J. Desborde popular y crisis del Estado. Lima: IEP, 1984.

MENDEZ, J.; O’DONNELL, G.; PINHEIRO, P. S. (eds.). La (in)efectividad de la ley y la exclusión en América Latina. Buenos Aires: Paidós, 2002.

MERKLEN, D. Les chasseurs urbains: une figure de l'individu en milieu populaire. In: CARADEC, V.; MARTUCCELLI, D. (eds.). Matériaux pour une sociologie de l'individu. Villeneuve d'Ascq: Presses Universitaires du Septentrion, 2004, p. 57-74.

MICHELETTI, M. Political Virtue and Shopping. London: Palgrave Macmillan, 2013.

MICHELS, R. Les partis politiques. Paris: Flammarion, 1971.

NINO, C. Un país al margen de la ley. Buenos Aires: Emecé, 2005

OBERSCHALL, A. Social Conflict and Social Movements. Englewood Cliffs: Prentice Hall, 1973.

OLSON, M. Logique de l'action collective. Paris: P.U.F., 1978.

PÉREZ SÁINZ J. P. La rebelión de los que nadie quiere ver. Buenos Aires: Siglo XXI, 2019.

PIZZORNO, A. Sur la rationalité du choix démocratique. In: BIRNBAUM, J.; LECA, J. (eds.). Sur l'individualisme. Paris: Presses de Sciences Po, 1991, p. 330-369.

RAMOS, C. La transformación de la empresa chilena. Santiago: Editorial Universidad Alberto Hurtado, 2009. 
ROBLES, F. El desaliento inesperado de la modernidad. Santiago: RIL Editores, 2000.

SENNETT, R. La corrosión del carácter. Barcelona: Anagrama, 2000.

SOMBART, W. Pourquoi le socialisme n'existe-t-il pas aux Etats-Unis? Paris: P.U.F, 1992.

SORJ, B;. MARTUCCELLI, D. El desafío latinoamericano. Buenos Aires: Siglo XXI, 2008.

SOUZA, J. Os batalhadores brasileiros. 2. ed. Belo Horizonte: Editora UFMG, 2012.

TOCQUEVILLE, A. De la démocratie en Amérique. Paris: Gallimard, 1961. 2 tomos.

TOURAINE, A. La parole et le sang. Paris: Odile Jacob, 1988.

ZAPATA, F. Autonomía y subordinación en el sindicalismo latinoamericano. México: F.C.E., 1993.

\section{Sobre los Autores}

Kathya Araujo es licenciada en Psicología por la Pontificia Universidad Católica del Perú y doctora en Estudios Americanos por la USACH. Investigadora de IDEA, Universidad de Santiago de Chile, y directora del Centro Núcleo Milenio Autoridad y Asimetrías de Poder.

Danilo Martuccelli es licenciado en Filosofía de la Universidad Nacional de Córdoba y doctor en Sociología por la EHESS, Paris. Profesor de Sociología en la Université de Paris y investigador en la Universidad Diego Portales. Investigador senior del Centro Núcleo Milenio Autoridad y Asimetrías de Poder

Recibido: 04 Sep 2019

Aceptado: 08 Mayo 2020 